\title{
Mobile Health in Uganda: A Case Study of the Medical Concierge Group
}

\author{
Louis H. Kamulegeya, ${ }^{a}$ Joseph Ssebwana, ${ }^{a}$ Wilson Abigaba, ${ }^{a}$ John M. Bwanika, ${ }^{a}$ Davis Musinguzi ${ }^{a}$ \\ aThe Medical Concierge Group, Kampala, Uganda \\ Correspondence to Louis H. Kamulegeya (lovis@tmcg.co.ug)
}

\begin{abstract}
The ubiquity of mobile phones offers an opportunity for a paradigm change in health-care delivery, which may offer solutions to some of the challenges faced by the health sector in Uganda. The Medical Concierge Group (TMCG) is a digital health company, headquartered in Uganda, which leverages on mobile phone-based platforms - such as short messaging service (SMS), voice calling - and social media to deliver health services. Just over two-thirds (68\%) of users of TMCG's services are males between 18 and 30 years of age. SMS reminders have improved the honouring of health facility appointments among HIV-positive clients, from $60 \%$ to $90 \%$; retention rates at supported health facilities have improved from $45 \%$ to $89 \%$. Furthermore, information dissemination has been achieved via mobile SMS, wherein subscribers can access health content on diverse topics - such as HIV/AIDS prevention and family planning - by sending messages to a pre-defined short code to a phone line. Over 900 beneficiaries have accessed health content via SMS subscriptions. Social media platforms, including Facebook and Twitter, are used for health information dissemination and have enabled a wider reach to over 13 million beneficiaries accessing health information on TMCG's Facebook page alone. Tailoring mobile phone-based health content to meet the target beneficiaries' needs is critical for TMCG's impact and uptake. With rising rates of phone ownership and Internet connectivity in Uganda, mobile phones offer an affordable and proven adoptable avenue to overcome the chronic challenges faced by the health sector.
\end{abstract}

\section{INTRODUCTION}

$\mathbf{T}^{\circ}$ o date, mobile health (mHealth) does not have a standard definition. For the purposes of this article, we adopted the World Health Organization's definition, which refers to mHealth as a component of electronic health that deals with the provision of health services and information via mobile technologies. ${ }^{1}$ Uganda's phone ownership rate increased from $10 \%$ in 2002 to $65 \%$ in $2014 .^{2}$ This has driven different sectors within the country - including the health sector - to leverage the ubiquity of mobile phones to improve services. ${ }^{3}$

Mobile technologies have great potential to overcome challenges in health-care delivery, as they provide cost-effective means of accessing quality health-care services. ${ }^{4}$ Such technologies provide an avenue for addressing some of the challenges that are of particular concern for health systems in developing countries, including low health worker-to-patient ratios, accessibility and transport to health facilities, poor health information systems, long waiting times at health facilities, and the poor or non-existent patient follow-up systems. ${ }^{5}$

This article discusses health-care delivery through mobile technologies, as implemented by The Medical Concierge Group (TMCG), a digital health company in Uganda.

\section{mHealth in Uganda}

The integration of digital technologies in health-care delivery in Uganda has gained momentum in past decade, coinciding with increased access to the Internet across the coutnry. ${ }^{6}$ Mobile phones provide an ideal means of targeted health information dissemination because of their portability and ubiquity. ${ }^{7-9}$ Short messaging service (SMS) functionality is used, for example, in aspects of disease surveillance as well as patient notifications - to remind people about health facility appointment dates or to take their medications - all as means of improving public health outcomes. ${ }^{10,11}$

Interventions relying on mHealth have also been implemented to improve health worker performance; for example, during Malaria Consortium's programme implementation in the northern and eastern parts of Uganda, text messaging was used to increase awareness and improve coverage of intermittent preventive treatment for malaria among health workers. ${ }^{12}$ Additionally, mobile phones have been used to facilitate remote consultations among health workers. ${ }^{13}$

Mobile phone approaches have also been used for the timely delivery of medical laboratory test results. A 
study done in southwestern Uganda revealed a high level of acceptability of text messaging as a mode of delivery for laboratory investigation results among a cohort of HIV-positive clients. ${ }^{14}$ Mobile technologies have also been used for data and information collection, for example, by the Uganda Ministry of Health for tuberculosis and malaria monitoring. ${ }^{12}$

In Uganda, mHealth programmes have employed a variety of strategies and technologies, including SMS - which accounts for the majority of mobile phone-based health services - as well as personal computers, personal digital assistant-based applications. Web-based applications and voice calls - for example, with interactive voice recognition (IVR) or even call-in services - have also gained momentum. ${ }^{12}$

\section{METHODS}

TMCG was chosen for this case study, which was conducted from October 2016 to October 2017 because it has operated a functional mHealth platform for the past 7 years and, therefore, provides an appropriate example of the landscape of mHealth implementation in Uganda. Focus group discussions with key personnel at TMCG were scheduled; these included l company director, 1 health-care worker, and the senior software engineer at the company. Data were also collected via a researcher-administered, open-ended questionnaire that covered details about the mobile phone platforms deployed and how they are used, the target beneficiaries, and the kinds of health services they facilitate.

Demographic information about the end users of the mHealth services - including age, gender, and location - was collected from the databases of the different mHealth platforms assessed. Additionally, we analysed anonymised user data, including HIV status information, categories of health enquiries made, and health services utilised. These data are routinely collected on an optional basis and documented within the different service provision platforms. The data, when exported from the different digital health platforms, was made available in the form of Excel (Microsoft Corp., Redmond, WA, USA) spreadsheets for analysis within Microsoft Excel 2018.

\section{RESULTS}

\section{The Medical Concierge Group}

TMCG is a digital health company, headquartered in Kampala, Uganda, which has been operational since 2012. TMCG operates a call centre that provides free access to health professionals 24 hours a day, 7 days a week, for anyone seeking health consultations or information. ${ }^{15}$

\section{Company Mission}

The mission of the company is "to design and deploy scalable models for unlimited access to holistic, affordable, and quality health-care products and services guided by innovation and user engagement". The company has achieved this through deploying a combination of concepts in health-care delivery via mobile technologies, including voice calling, SMS, social media platforms (Facebook and Twitter, for example), and messaging services (like WhatsApp). Focusing on live interactions to provide a unique personal experience of individualized responses in every interaction is the main objective of the company's model of mHealth delivery.

\section{Voice Calling Services}

The voice calling platform allows for immediate and real-time interactions between health workers and end users. Data are collected using an open source application called Asterisk. ${ }^{16}$ The voice calling platform is used to handle health-related enquiries, coordinate care for chronically ill patients, facilitate treatment adherence, assist in the retention of patients in care, follow-up antenatal care clients, and contribute to pharmacovigilance.

The majority voice platform users are males $(60 \%)$ between 18 and 35 years of age (80\%). Calls are received from different parts of the country, but the majority $(67.2 \%)$ come from the central region.

Interactions cut across different health domains, with those related to HIV/AIDS accounting for 30.6\%. Most HIV/ AIDS-related enquiries deal with myths and misconceptions about HIV transmission and prevention. Enquiries about sexual and reproductive health account for $10.6 \%$ of interactions, and these cover topics such as family planning and menstrual hygiene. Maternal, newborn, and child health concerns account for $12.7 \%$ of interactions, and gastrointestinal complaints account for $9.2 \%$.

\section{Messaging Services}

TMCG's messaging service involves both pushes and pulls. With push interactions, users consent to receiving mobile messages with health information. For pull messaging services, individuals subscribe to mHealth content by sending a keyword to a short code. For example, to receive messages about family planning, a user sends the keyword "FP" to 8884. HIV/AIDS prevention, with 282 subscriptions, is the most highly subscribed topic, followed by family planning (270 subscriptions); adolescent health (201 subscriptions); and maternal, newborn, and child health (153 subscriptions).

For the push system, the SMS platform was integrated into RapidPro, ${ }^{17}$ an open source messaging software application that is used for health campaigns, wherein content including reminders - can be sent to beneficiaries. Monthly reminders were sent to 10,371 clients on antiretroviral treatment, and this improved the appointment uptake rate from $60 \%$ to $90 \%$ which consequently improved client retention at supported health facilities.

Additionally, health content is disseminated via mobile messages that cover different thematic areas, including family planning; maternal, newborn, and child health; and HIV/ AIDS awareness and prevention, among others. The mobile messages are available in different local languages. In addition to being used for health information dissemination, the SMS platform can be used for individualised case management based on client enquiries, allowing personalised interactions between health workers and end users. 
FIGURE 1. The Telehealth Voice Workflow

A beneficiary who calls into the call centre (1) is answered by the doctor who addresses the caller's health inquiry (2), for example, by referring the client to a health service or offering health advice. The doctor documents a summary of the call into the electronic records system for archving in the a database (3).

FIGURE 2. The Telehealth Short Messaging System (SMS) Workflow

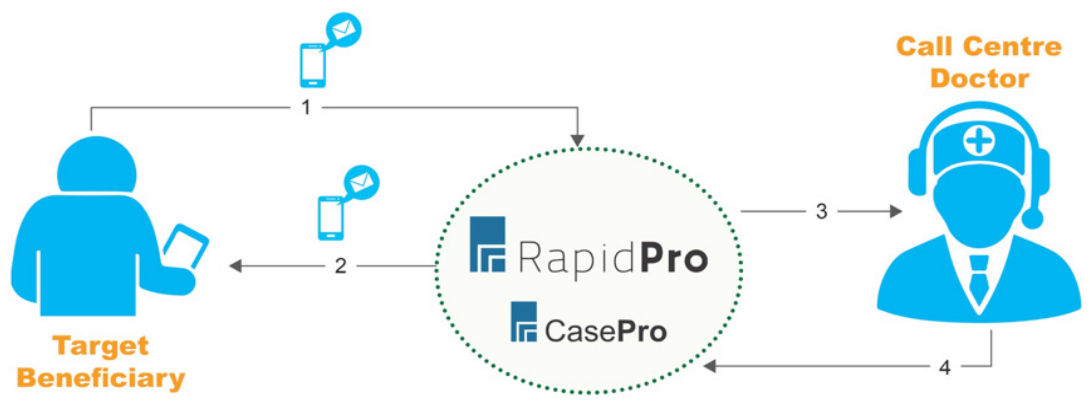

End users can use the SMS platform in 2 ways. In case they need to access health information on any health-related topic, they send in a key word to a predetermined short-code (1) to access related content housed in an messaging application called RapidPro (2). Alternatively, a beneficiary with a health enquiry can send a questions (3) to be addressed by a doctor at the call centre (4) on the CasePro platform, which allows for individualised responses.

\section{Social Media Platforms}

TMCG uses its social media accounts on Facebook (https:// www.facebook.com/TMCGLtd/) and Twitter (https://twitter. com/TMCGLtd) to reach a much larger audience for information dissemination. Health content to be shared on the pages undergoes a development process that starts with, for exam- ple, a topic chosen according to a date specified by the international health calendar or any major health event in the country. After the topic is chosen, data and research are compiled to inform content curation, after which the content is organised, reviewed, and revised before it is posted, shared, or otherwise disseminated. Metrics reflecting the impact of the 
TABLE. Demographic Characteristics of Voice Call Service Users

Characteristics

n (\%)

\section{Gender}

Males

$8,015(68 \%)$

Females

$3,779(32 \%)$

Age range, years

$<18$

$317(2.7 \%)$

$18-30$

8,469 (71.8\%)

$31-50$

$2789(23.6 \%)$

51-100

$219(1.9 \%)$

Voice service utilisation by region

Central

Eastern

$1,613(13.6 \%)$

Western

$1,479(12.5 \%)$

Northern

$269(2.4 \%)$

West Nile

$500(4.3 \%)$

Top 5 districts by call-in traffic

$\begin{array}{lc}\text { Kampala } & 4,790(40 \%) \\ \text { Wakiso } & 742(6.0 \%) \\ \text { Masaka } & 664(5.0 \%) \\ \text { Jinja } & 424(6 \%) \\ \text { Mbale } & 389(3.0 \%) \\ \text { Others } & 4,782(40 \%)\end{array}$

social media content are compiled using the indices provided by the social media platforms; for example, post engagements (the number of times people have commented, shared, or liked a post), page recommendations, reach (number of people that have interacted with a post), among others. For example, in 2017, the company's Facebook page had 246,984 followers with a reach of $13,181,870$ people and up to 744,986 logged-in viewers.

\section{DISCUSSION}

The 24 million mobile subscribers ${ }^{18}$ and 13 million Internet users in Uganda represent a huge opportunity for overcoming barriers hindering universal health-care accessibility in the country. Social media, in particular, can reach far more people in a shorter period of time, and at a lower cost, than the traditional methods of cascading health information through physical gatherings. ${ }^{19}$

According to TMCG data, mHealth strategies have shown to be effective at reaching male clients, whose poor health-seeking behaviour has been shown to pose challenges that hinder preventive health programming and interventions. ${ }^{20}$ Among other factors, men are often discouraged from seeking health-care services because of long waiting hours at health facilities, fear of projecting weakness instead of the perceived expectation of "manliness", and the low levels of privacy at many health facilities. ${ }^{20}$ Despite these barriers and the well-established pattern of the relatively low uptake of health-care services by men relative to women, during the study period, $68 \%$ of TMCG's voice calling service users were males, and $32 \%$ were females.

Mobile phone features, such as SMS, offer opportunities for improving patient outcomes. For example, daily SMS reminders for asthmatic patients have been shown to increase adherence to treatment over 3 months of follow-up. ${ }^{21}$ In rural Uganda, SMS reminders for patients on antiretroviral therapy led to improved adherence. ${ }^{22}$ The TMCG data corroborate these study findings, as users of TMCG mHealth services exhibited improved hospital appointment uptake and retentions in HIV care programmes (Figure 3 ).

Important considerations for SMS platforms and content include contextualisation, comprehensibility, and accessibility tailored to the target audience..$^{23}$ Multi-language support is, therefore, a key feature of TMCG's messaging platforms. Additionally, continuous content review, feedback, and editing are necessary for content to remain relevant and useful. This is exemplified by TMCG's social media content development process flow.

The limitations of mHealth interventions in low-income countries - especially in remote, rural areas - may include inaccessibility to mobile technology and the Internet. TMCG's mHealth clients are disproportionately distributed in urban areas, particularly in Kampala and Wakiso.

\section{CONCLUSION}

Mobile phone-based health innovations provide an affordable and flexible way to overcome the chronic challenges to health-care delivery in Uganda, including the low doctor-to-patient ratio, long waiting times at health facility, and poor or non-existent patient follow-up systems. Such mHealth services allow for large numbers of beneficiaries to be served at minimal expenditure of time and resources relative to traditional models of health-care delivery, which require physical interactions in most circumstances. Mobile technologies are particularly useful for preventive interventions, such as behavioural change communication for HIV/ AIDS prevention. 


\section{FIGURE 3. The Retention Rates of HIV-positive Clients Under Care at Facilities Implementing Mobile Health (mHealth) Interventions}

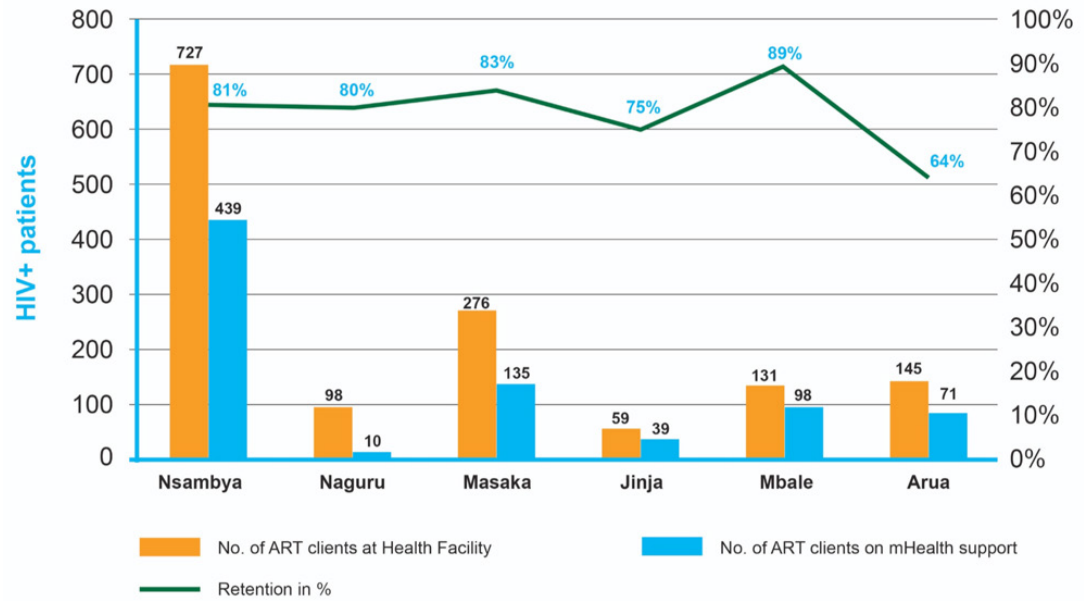

Facilities with more clients consenting to receive mHealth support have higher retention rates.

The TMCG further reaffirms the effectiveness of SMS for improving patient outcomes, especially for chronically ill patients, for example, in terms of improved adherence to hospital appointments among HIV-positive clients. The demographic reach of TMCG's mobile phone-based platforms - notably of particular interest to males and clients of both genders between 18 and 30 years old - provides insight to the plausibility of pilot mHealth interventions targeting men and young people. Effective communication via mobile phonebased channels requires targeted messaging that is tailored to the needs of the audience, easy to understand, and context-specific for the beneficiaries, even if it means translating messages and content to local languages. Finally, given the potentially sensitive nature of health data, ensuring data security and patient confidentiality is critical if the growth of such platforms is to be realised and sustainable.

Acknowledgements: We would like to acknowledge the staff of TMCG, who took the time to take part in the interviews, as well as the graphic designer, Michael Katerega, who helped in the designing of the illustrations used in the article. Funding for the study was from TMCG.

\section{REFERENCES}

1. World Health Organization (WHO). mHealth: New Horizons for Health Through Mobile Technologies. Geneva: WHO; 2011. https://apps.who.int/ iris/handle/10665/44607. Accessed 12 March 2019.

2. Pew Research Center. Cell phones in Africa: communication lifeline. Pew Research Center Website. http://www.pewglobal.org/2015/04/15/ cell-phones-in-africa-communication-lifeline/. Accessed 12 March 2019.

3. Munyegera GK, Matsumoto T. Mobile money, remittances, and household welfare: panel evidence from rural Uganda. World Dev. 2016;79:127-137. CrossRef

4. Ryu S. Telemedicine: Opportunities and developments in member states: report on the Second Global Survey on eHealth 2009 (Global Observatory for
eHealth Series, Volume 2). Healthc Inform Res. 2012;18(2):153-155. CrossRef

5. Aranda-Jan CB, Mohutsiwa-Dibe N, Loukanova S. Systematic review on what works, what does not work and why of implementation of mobile health (mHealth) projects in Africa. BMC Public Health. 2014;14:188. CrossRef. Medline

6. Huang F, Blaschke S, Lucas $\mathrm{H}$. Beyond pilotitis: taking digital health interventions to the national level in China and Uganda. Global Health. 2017;13:49. CrossRef. Medline

7. Mitchell KJ, Bull S, Kiwanuka J, Ybarra ML. Cell phone usage among adolescents in Uganda: acceptability for relaying health information. Health Educ Res. 2011;26(5):770-781. CrossRef. Medline

8. de Lepper A, Eijkemans M, van Beijma V, Loggers JW, Tuijn CJ, Oskam L. Response patterns to interactive SMS health education quizzes at two sites in Uganda: a cohort study. Trop Med Int Health. 2013;18(4):516-521. CrossRef. Medline

9. Roberts S, Birgisson N, Chang JD, Koopman C. A pilot study on mobile phones as a means to access maternal health education in eastern rural Uganda. J Telemed Telecare. 2015;21(1):14-17. CrossRef. Medline

10. Asiimwe C, Gelvin D, Lee $E$, et al. Use of an innovative, affordable, and opensource short message service-based tool to monitor malaria in remote areas of Uganda. Am J Trop Med Hyg. 2011;85(1):26-33. CrossRef. Medline

11. Kunutsor S, Walley J, Katabira E, et al. Using mobile phones to improve clinic attendance amongst an antiretroviral treatment cohort in rural Uganda: a cross-sectional and prospective study. AIDS Behav. 2010;14(6):1347-1352. CrossRef. Medline

12. Mwagale M, Kakaire F. Mobile Health Projects in Uganda - Narrative Report. Kampala, Uganda: Uganda Chartered Healthnet; 2010. https://www.malariaconsortium.org/upscale/local/downloads/1206-mhealth-projects-in-uganda. pdf. Accessed 12 March 2019.

13. Chang LW, Kagaayi J, Arem $\mathrm{H}$, et al. Impact of a mHealth intervention for peer health workers on AIDS care in rural Uganda: a mixed methods evaluation of a cluster-randomized trial. AIDS Behav. $2011 ; 15(8): 1776-1784$. CrossRef. Medline

14. Siedner MJ, Haberer JE, Bwana MB, Ware NC, Bangsberg DR. High acceptability for cell phone text messages to improve communication of laboratory results with HIV-infected patients in rural Uganda: a cross-sectional survey study. BMC Med Inform Decis Mak. 2012;12:56. CrossRef. Medline 
15. The Medical Concierge Group (TMCG). Annual Report 2018. Kampala, Uganda: TMCG; 2018. http://www.tmcg.co.ug/publications/. Accessed 12 March 2019.

16. Van Meggelen J, Madsen L, Smith J. AsteriskTM: The Future of Telephony. 2nd ed. Sebastopol, CA, USA: O'Reilly Media; 2017. https://book.huihoo.com/ $\mathrm{pdf} /$ asterisk-the-future-of-telephony/AsteriskTFOT-2.pdf. Accessed 12 March 2019.

17. Haßler B, Brugha M, Muyoya C, Mitchell J, Hollow D, Jackson A. Donor Organizations \& the Principles for Digital Development: A Landscape Assessment and Gap Analysis. https://digitalprinciples.org/wp-content/uploads/ PDD2018_interactive.pdf. Accessed 12 March 2019. CrossRef

18. Uganda Communications Commission (UCC). Post, Broadcasting and Telecommunications Market \& Industry Q3 Report. Kampala, Uganda: UCC; 2017. https://www.ucc.co.ug/wp-content/uploads/2018/02/Market-Industry-Quarterly-Report-for-the-Quarter-ending-September-2017-Final.pdf. Accessed 12 March 2019.

19. Scanfeld D, Scanfeld V, Larson EL. Dissemination of health information through social networks: Twitter and antibiotics. Am J Infect Control. 2010;38(3):182188. CrossRef. Medline

20. Galdas PM, Cheater F, Marshall P. Men and health help-seeking behaviour: literature review. J Adv Nurs. 2005;49(3):616-623. CrossRef. Medline

21. Strandbygaard U, Thomsen SF, Backer V. A daily SMS reminder increases adherence to asthma treatment: a three-month follow-up study. Respir Med. 2010;104(2):166-171. CrossRef. Medline
22. Ware NC, Pisarski EE, Tam M, et al. The Meanings in the messages: how SMS reminders and real-time adherence monitoring improve antiretroviral therapy adherence in rural Uganda. AIDS. 2016;30(8):1287-1294. CrossRef. Medline

23. Mbuagbaw L, Bonono-Momnougui RC, Thabane L. Considerations in using text messages to improve adherence to highly active antiretroviral therapy: a qualitative study among clients in Yaoundé, Cameroon. HIV AIDS (Auckl). 2012;4:45-50. CrossRef. Medline

\section{Peer Reviewed}

Competing Interests: The authors are all employed by The Medical Concierge Group. The Medical Concierge Group funded this work.

Received: 6 Jul 2018; Accepted: 7 Mar 2019

Cite this article as: Kamulegeya LH, Ssebwana J, Abigaba W, Bwanika JM, Musinguzia D. Mobile Health in Uganda: A Case Study of the Medical Concierge Group. E Afr Sci. 2019;1(1):9-14. https://doi.org/10.24248/EASci-D-18-00005.

(c) Kamulegeya et al. This is an open-access article distributed under the terms of the Creative Commons Attribution License, which permits unrestricted use, distribution, and reproduction in any medium, provided the original author and source are properly cited. To view a copy of the license, visit http://creativecommons.org/ licenses/by/4.0/. When linking to this article, please use the following permanent link: http://doi.org/10.24248/EASci-D-18-00005. 